\title{
MONITORING METHODS AND PROGNOSIS OF OPOMYZA FLORUM FABR. (DIPTERA: OPOMYZIDAE) - A PEST OF WHEAT IN BULGARIA
}

\author{
Hristina Krusteva*, Olia Karadjova, Ventsislav Ventsislavov \\ Institute of Soil Science, Agrotechnologies and Plant Protection "Nikola Pushkarov" \\ 35 Panajot Volov str. 2230 Kostinbrod, Bulgaria
}

Received: March 21, 2012

Accepted: October 12, 2012

\begin{abstract}
The effect of sowing dates on the abundance of Opomyza florum, and the effect of sowing dates on the degree of larvae damage on winter wheat during the 2003-2008 time period was evaluated. The population density of $O$. florum adults and the damage larvae caused, were higher in the wheat fields sown in the last decade of September and the first half of October. Fields sown during the first decade of November were not infested by $O$. florum. A significant correlation between the mean temperature during the flight period and the maximum density of $O$. florum flies within each sowing $(r=0.94 ; p=0.016)$ was established. The percentage of damaged shoots strongly corresponded to the maximum abundance of flies $(r=0.96 ; p=0.01)$. The corresponding figures can be used for prognostic purposes. An adult observation accuracy below $25 \%$ was achieved by the sweep net method using 10 samples of 30 sweeps in the beginning of migration and 10 samples of 20 sweeps during the period of the O. florum mass flight. No marginal effect of adults was observed.
\end{abstract}

Key words: Damaged shoots, density dynamics, monitoring, sowing date, Opomyza florum, winter wheat

\section{INTRODUCTION}

The grass and cereal fly (yellow wheat fly) Opomyza florum (Fabricius 1794) is one of the most damaging pests on winter wheat in Bulgaria (Ljubenov 1956; Samfirov 1961, 1966; Krusteva 2002, 2003; Krusteva et al. 2006; Ventsislavov and Krusteva 2006; Krusteva et al. 2011). Larval feeding results in damage to wheat shoots and a lower grain yield.

According to the literature, the most effective method of controlling this pest is by planning the sowing date. Wheat fields which are sown early are more densely inhabited and damaged more severely by O. florum (Thomas 1933; Slope 1957; Samfirov 1966; Stamenkovic 1980; Short 1981; Zagovora et al. 1981; Vickerman 1982). In Bulgaria, there is little information about the relationship between the sowing date of winter wheat and the damage rate of O. florum larvae in shoots (Samfirov 1966; Krusteva and Ventsislavov 2004; Ventsislavov and Krusteva 2006). Studies conducted in the country were not sufficient enough to explain the impact of climatic conditions on adult density dynamics (Ventsislavov and Krusteva 2006). The influence of sample size and distribution of $O$. florum adults within the field, on the accuracy of estimated adult fruit fly density has never been studied in Bulgaria. In accordance with the literature data these factors are of great importance for the formulation of efficient sample collecting schemes using the sweepnet method (Southwood and Henderson 2000).
The objective of this study was to formulate an efficient monitoring procedure based on the accuracy of estimated adult $O$. florum density [with Relative Variance \%, (RV\%) below 25\%].

\section{MATERIALS AND METHODS}

The studies were conducted in winter wheat fields at the Plant Protection Institute near Kostinbrod and in the Montana region of Bulgaria during the 2003-2008 time period. The investigated winter wheat fields in Kostinbrod were sown on September 26, October 14 and November 10 (2003), September 24, October 10 and 25 (2004), September 29, October 13 and 26 (2005), October 4 and 23 (2006), September 26 and October 11) (2007) and September 30, October 10 and 22 (2008). The density dynamics of O. florum adults were observed at intervals of 2-3-10 days starting from seedling emergence and ending when daily temperatures fell below $4^{\circ} \mathrm{C}$. The samples were collected by sweep-net in 5 sets of 20 sweeps for each observed date and field. The rule of " 5 sweeps $=1 \mathrm{~m}^{2}$ " (Mihailova et al. 1982) was used to calculate the number of flies $/ \mathrm{m}^{2}$. To investigate the incidence of damaged shoots, 6-12 plant samples from 0.5 linear $\mathrm{m}$. were collected systematically for each sowing date Collections took place from the end of March, when the first damage was observed, until the end of stem elongation. Shoot injury was presented in percentage of the total amount of shoots/0.5 linear meters. 
Studies on the distribution of O. florum adults at different distances from the edge of the fields were conducted in the Montana region in 2004 and 2008. Two types of fields were investigated: a sowing on even terrain (60 ha) and a sowing on uneven terrain (50 ha). The fly density dynamics were observed using a sweep-net with variants of 5,10,20,50, and $100 \mathrm{~m}$ from the edge of the fields (20 sweeps in 5 repetitions for each variant). An evaluation of sample size on the accuracy of estimated adult O. florum density using the sweep-net method, was conducted in the Kostinbrod region during the 2004-2005 time period. Fly density was registered with variants of 10, 20, and 30 sweeps, each in 5 repetitions. Data were analyzed with SPSS 16.0 (Statistical Package for the Social Sciences) statistical software. The significance for statistical analysis was set at $p \leq 0.05$. The relative standard error (Relative Variance - RV\%) was used to evaluate the accuracy of the estimations (Southwood and Henderson 2000).

\section{RESULT AND DISCUSSION}

O. florum has one generation annually. In the area of Kostinbrod, adults emerged in the second and third decade of May. They are sexually immature and remain in a reproductive diapause until the end of September. During this period, we found imagoes inhabiting the vicinity of dense oak and pine woods near rivers, bogs, and other damp places. Data from our study showed that $O$. florum adults start migrating to wheat plantings in the I-st and II-nd decade of October at the phenophase of first-second leaf. The adults inhabit the plantings by the end of November - beginning of December. They are then sexually mature and after mating, the females lay overwintering eggs on the ground near the wheat shoots. The larvae hatch in late March and mid April (average temperatures for the last decade above of $9^{\circ} \mathrm{C}$ ). They cut through the central leaf and the cone of elongation and feed on the embryonic tissue without injuring the node of tillering. Damaged shoots stop growing. The central leaf becomes yellow and twisted. The other leaves stay green but after the larvae complete their development, the shoots die.

The data presented in figures 1-6 show a significant fluctuation in the flying period of adults. Depending on the climatic conditions and plant emergence, the adult flying period varied from 35 (2007) to 60 (2005) days in fields sown in the III-rd decade of September, from 30 $(2003,2008)$ to $45(2005)$ days in fields sown in the I-st and II-nd decades of October, and from 15 (2006) to 25 (2005) days in fields sown during the last decade of October. O. florum did not infest fields sown during the first decade of November.

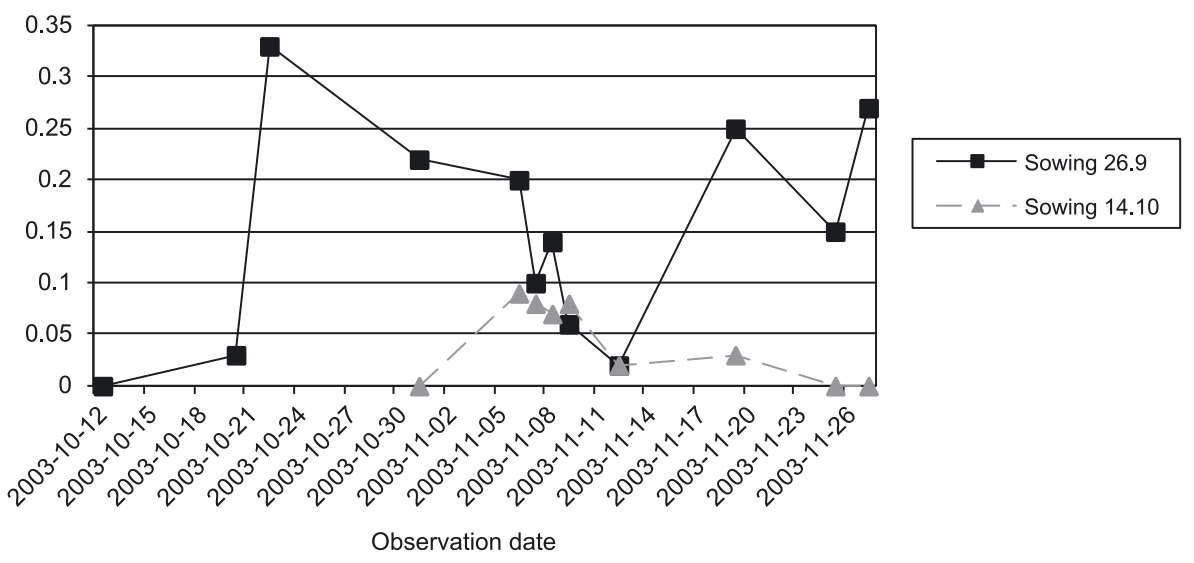

Fig. 1. Density dynamics of O. florum (flies $/ \mathrm{m}^{2}$ ) in relation to sowing date, 2003, Kostinbrod

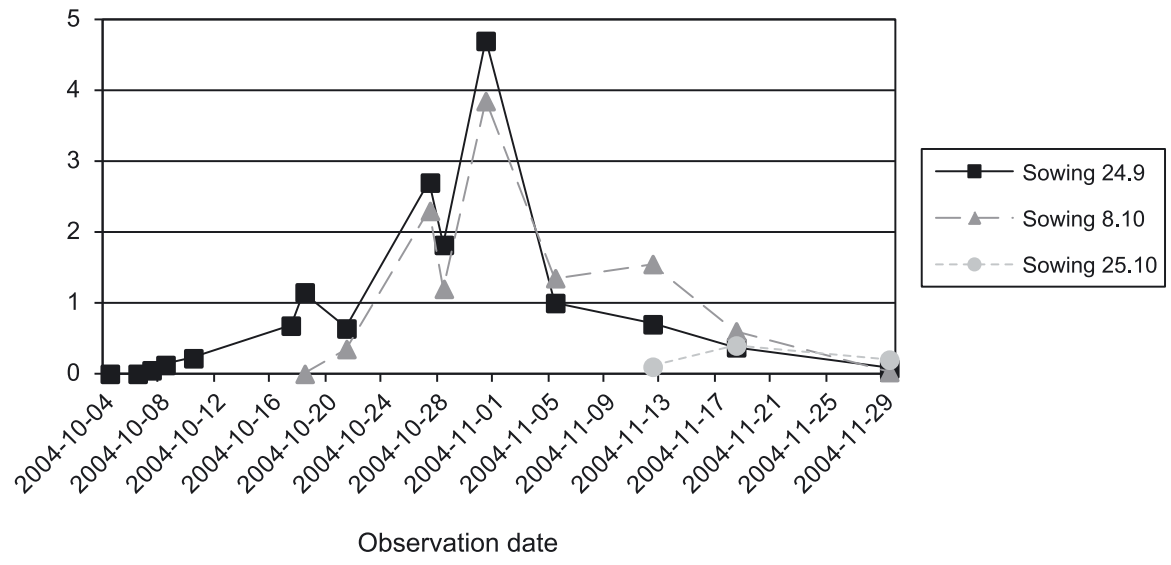

Fig. 2. Density dynamics of $O$. florum (flies $/ \mathrm{m}^{2}$ ) in relation to sowing date, 2004, Kostinbrod 


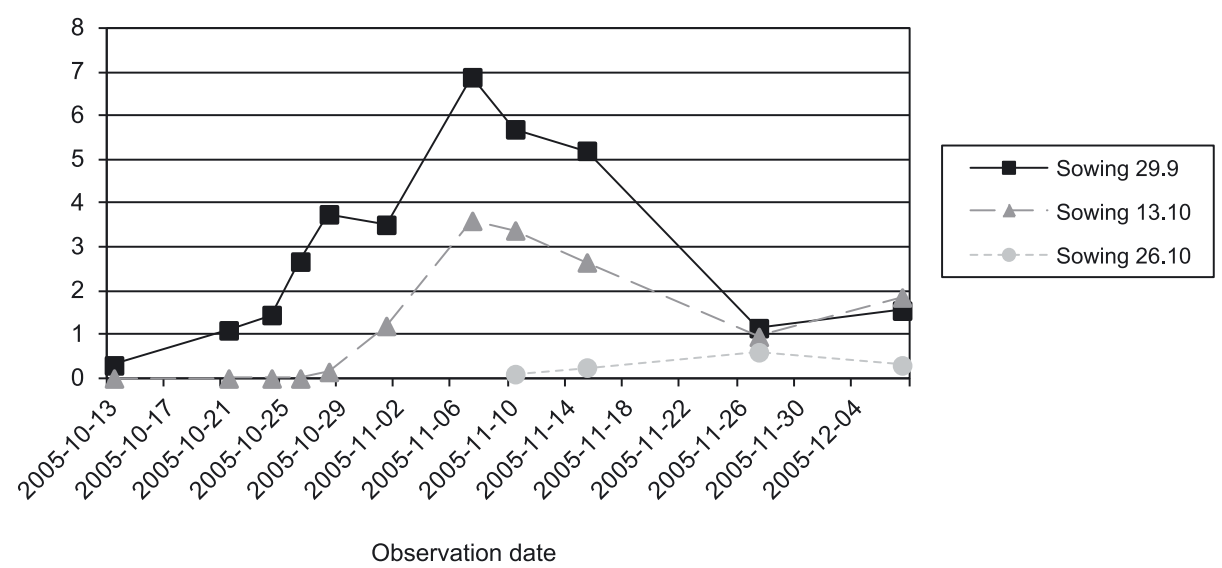

Fig. 3. Density dynamics of $O$. florum (flies $/ \mathrm{m}^{2}$ ) in relation to sowing date, 2005, Kostinbrod

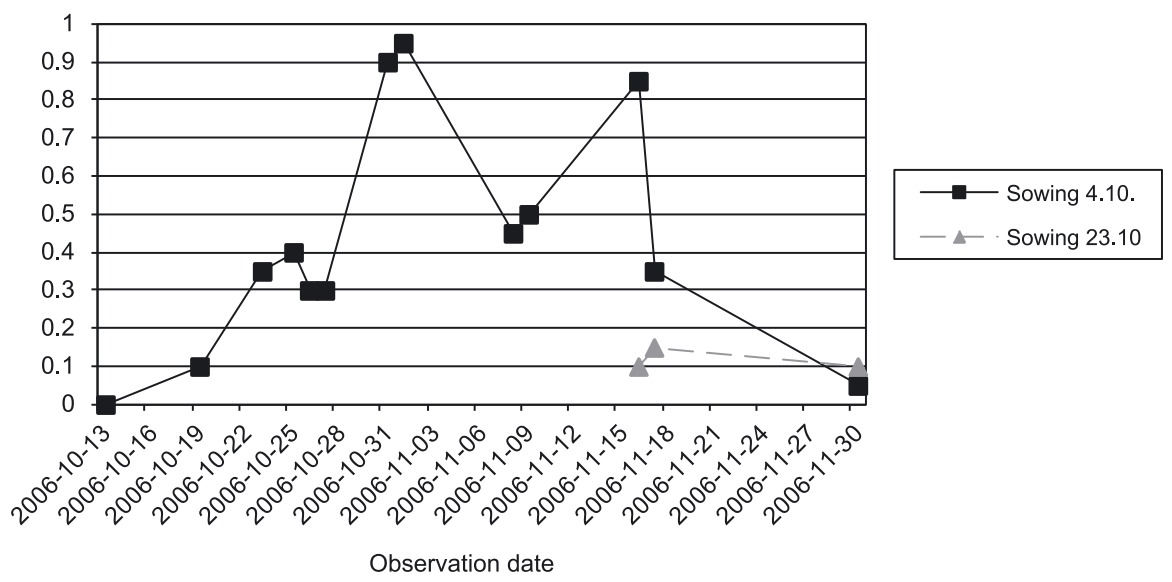

Fig. 4. Density dynamics of O. florum (flies $/ \mathrm{m}^{2}$ ) in relation to sowing date, 2006, Kostinbrod

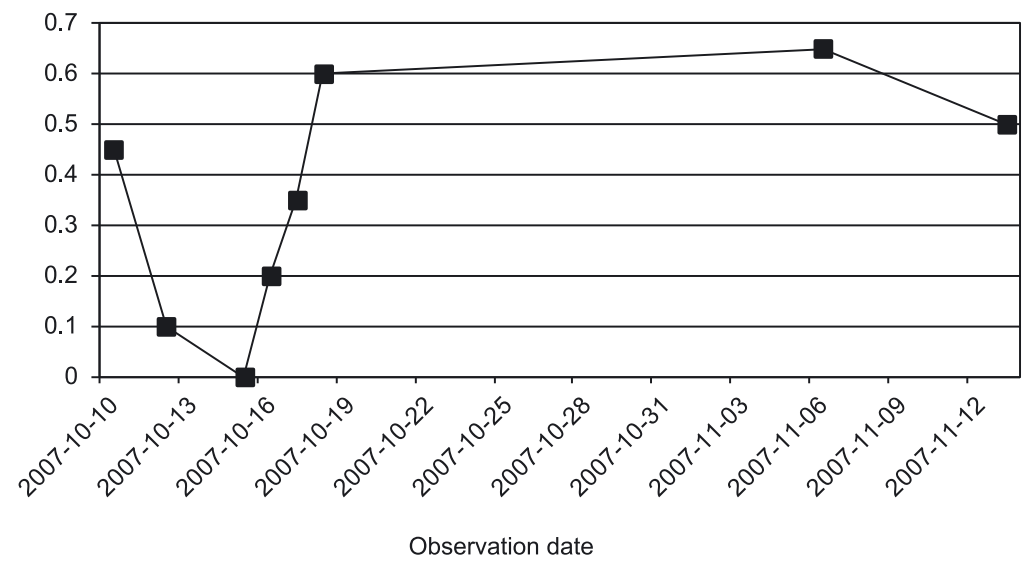

Fig. 5. Density dynamics of $O$. florum (flies $/ \mathrm{m}^{2}$ ) in relation to sowing date, 2007, Kostinbrod

There were significant differences in adult densities during the different years of the study and in the different sowings. In all of the studied years (2003-2008) the density of adults was greatest in wheat sown in the last decade of September (0.33-6.88 ind./ $\left.\mathrm{m}^{2}\right)$, followed by the density in fields sown in the first half of October (0.09-3.85 ind./ $\mathrm{m}^{2}$ ) and in fields sown during the last decade of October $\left(0.15-1.0\right.$ ind. $\left./ \mathrm{m}^{2}\right)$.
A mass flight of $O$. florum in the first and second sowings in 2004, 2005, and 2008 was observed during the end of October and in the first decade of November. This supposes that there is a variation in the abundance of adults between years due to differences in climatic conditions during the period of flight. Results of the statistical analysis showed a significant correlation between the mean temperature during the flight period and the maximum densities of $O$. florum flies within each sowing 


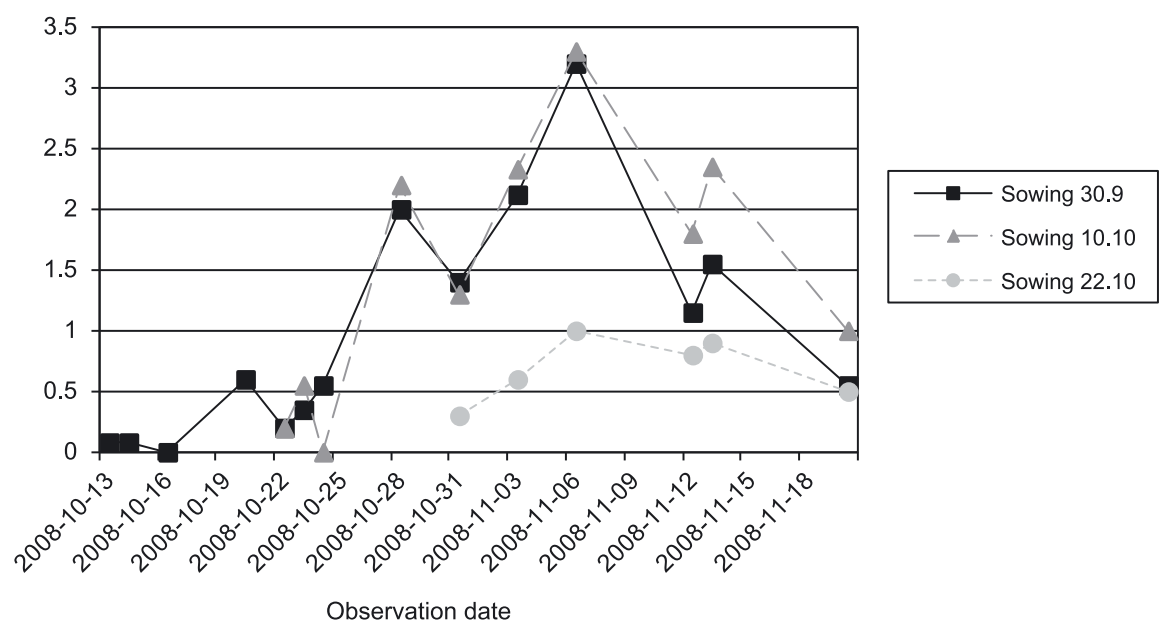

Fig. 6. Density dynamics of O. florum (flies $/ \mathrm{m}^{2}$ ) in relation to sowing date, 2008, Kostinbrod

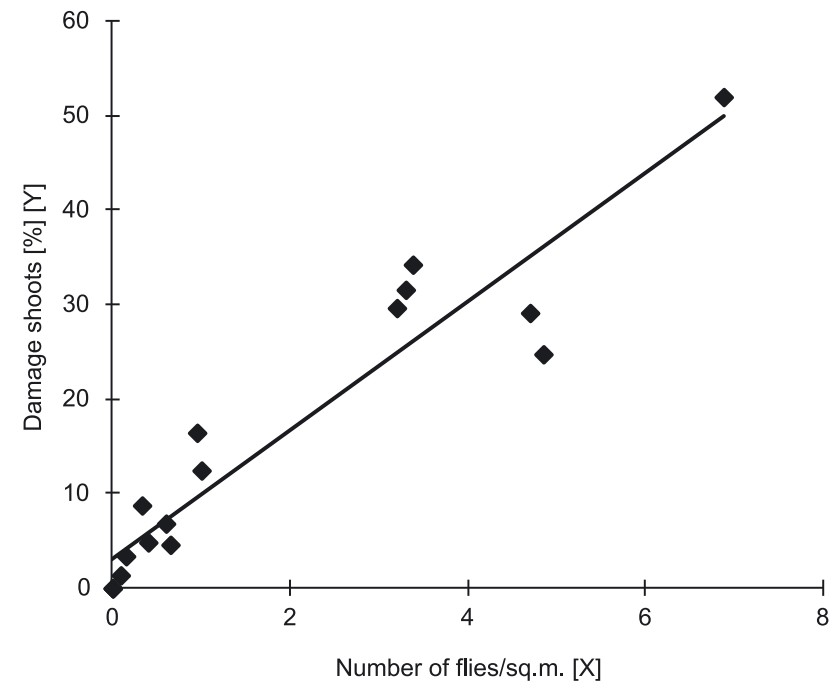

Fig. 7. Relationship between O. florum adult density $\left(\right.$ number $\left./ \mathrm{m}^{2}\right)$ and percent of shoots damaged by larvae

Table 1. Average daily temperatures (per decades) and monthly sum of precipitation ( $\mathrm{mm}$ ) during the flying period of $O$. florum, 2003-2004 (October and November), Kostinbrod

\begin{tabular}{|c|c|c|c|c|c|c|c|c|}
\hline \multirow{3}{*}{$\begin{array}{l}\text { Month } \\
\text { Decade }\end{array}$} & \multicolumn{6}{|c|}{ Average daily temperatures (per decades) } & \multicolumn{2}{|c|}{$\begin{array}{l}\text { Monthly sum of } \\
\text { precipitation [mm] }\end{array}$} \\
\hline & \multicolumn{3}{|c|}{ October } & \multicolumn{3}{|c|}{ November } & \multirow{2}{*}{ October } & \multirow{2}{*}{ November } \\
\hline & I & II & III & I & II & III & & \\
\hline 2003 & 15.7 & 9.2 & 9.3 & 8.9 & 5.4 & 6.7 & 99.4 & 35.2 \\
\hline 2004 & 14.2 & 11.6 & 15.4 & 10.3 & 6.7 & 2.5 & 37.8 & 47.7 \\
\hline 2005 & 12 & 8.5 & 11.3 & 7.3 & 4.6 & 4.5 & 61.1 & 29.1 \\
\hline 2006 & 13.9 & 6.8 & 11.4 & 2.9 & 5 & 5.4 & 64 & 33.3 \\
\hline 2007 & 13.6 & 7.5 & 7.3 & 4.4 & 1.8 & 0.5 & 134.4 & 132 \\
\hline 2008 & 13.6 & 13.4 & 11.8 & 12.8 & 6.5 & 1.7 & 43.4 & 14.3 \\
\hline Normal & 12.2 & 10.5 & 9 & 7 & 5.1 & 3 & & \\
\hline
\end{tabular}


$(y=7.039+1.06 x, r=0.94, p=0.016)$. In 2003, 2006, and 2007, the mean temperatures were lower in October and November, compared with the mean temperatures for the same period of 2004, 2005, and 2008 (Table 1).

As a result, the population of $O$. florum had a very low density $\left(0.33,0.95\right.$ and 0.65 ind. $/ \mathrm{m}^{2}$, respectively). The low population dynamics of O. florum in 2003 and 2007 were also due to a higher precipitation sum in October 2003 (99.4 mm), and in both October and November 2007 $(266.4 \mathrm{~mm})$ resulting in a weak flight activity of adults during their migration to wheat fields and a lower damage rate. The data showed that the percentage of damaged shoots strongly corresponds to the maximum abundance of adults $(\mathrm{y}=4.13+6.85 \mathrm{x}, \mathrm{r}=0.96, \mathrm{p}=0.01)$ and can be used for prognostic purposes (Fig. 7).
In conformity with the abundance of $O$. florum, the highest rates of damage by larvae were observed in the first and second sowings in 2004/2005, 2005/2006, and 2008/2009-29.13\%, 24.76 and 51.98, and 34.24, 29.65 and $31.58 \%$, respectively (Fig. 8 ).

The data on the mean density of $O$. florum at different distances from the edge of the wheat fields did not reveal a "marginal effect" pattern in the distribution of adults within the field. In sowings on even terrain (Table 2 ), there were no significant differences in the abundance of the pest at different locations in the field, thus diagonal sampling can be used. In sowings on uneven terrain (Table 3), the density of $O$. florum is significantly higher in locations which are shielded from the wind. In such cases, a different sampling scheme should be used to take into account these "protected" patches and their total area.

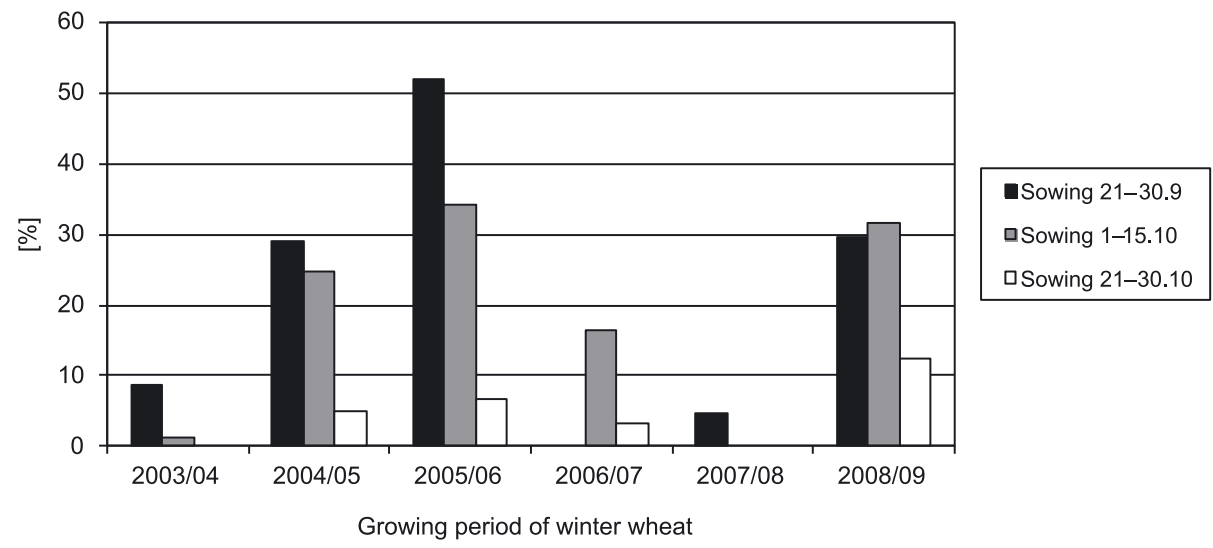

Fig. 8. Quantity of damaged shoots by larvae of O. florum (in \% of total amount of shoots/0,5 linear $\mathrm{m}$.) in relation to sowing date, Kostinbrod, 2003-2009

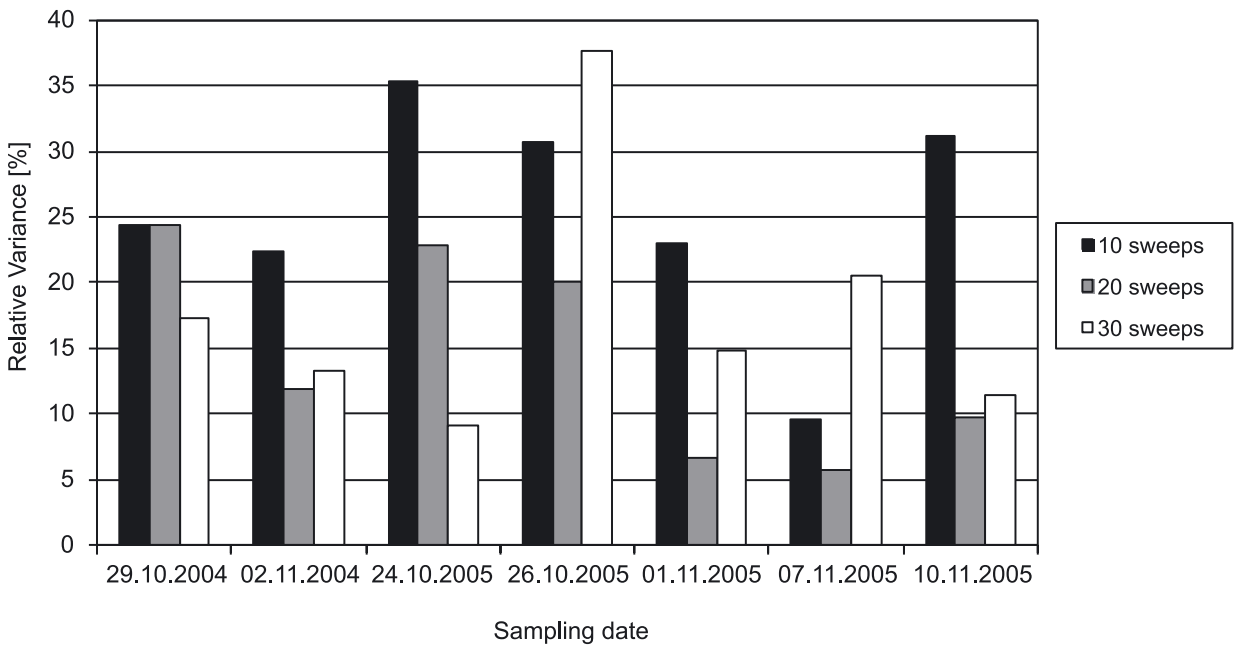

Fig. 9. Influence of sample size on the accuracy (Relative Variance \%) of estimated O. florum adult density (No./ $\mathrm{m}^{2}$ ) using the sweepnet method with samples of 10, 20, and 30 sweeps, Kostinbrod 
The differences in the numbers of adult $O$. florum per $\mathrm{m}^{2}$ observed between the collection variants with 10,20 , and 30 sweeps on all sampling dates in 2004 and 2005, except for one, are not significant (Table 4).

Table 2. Mean density (number of flies $/ \mathrm{m}^{2}$ ) of $O$. florum at 5,10 , 20 , 50, and $100 \mathrm{~m}$ from the edge of the wheat field with even terrain, Montana, 2008

\begin{tabular}{cccc}
\hline Distance $[\mathrm{m}]$ & $\begin{array}{c}\text { Mean density } \\
{[\mathrm{x}]}\end{array}$ & $\begin{array}{c}\text { Standart error } \\
{[\mathrm{Sx}]}\end{array}$ & RV\% \\
\hline 5 & $2.00 \mathrm{a} \pm$ & 0.40 & 20.00 \\
10 & $2.13 \mathrm{a} \pm$ & 0.15 & 7.04 \\
20 & $1.04 \mathrm{a} \pm$ & 0.22 & 21.15 \\
50 & $1.53 \mathrm{a} \pm$ & 0.27 & 17.64 \\
100 & $1.50 \mathrm{a} \pm$ & 0.20 & 13.33 \\
\hline
\end{tabular}

*means with the same letters are not significantly different at $\mathrm{p}>0.05 ; \mathrm{RV}$ - Relative Variance

Table 3. Mean density (number of flies $/ \mathrm{m}^{2}$ ) of $O$. florum at 5,10 , 20,50 , and $100 \mathrm{~m}$ from the edge of the wheat field with uneven terrain, Montana, 2004

\begin{tabular}{cccc}
\hline Distance $[\mathrm{m}]$ & $\begin{array}{c}\text { Mean density } \\
{[\mathrm{x}]}\end{array}$ & $\begin{array}{c}\text { Standart error } \\
{[\mathrm{Sx}]}\end{array}$ & RV\% \\
\hline 5 & $3.70 \mathrm{a} \pm$ & 0.55 & 14.86 \\
10 & $3.20 \mathrm{a} \pm$ & 0.44 & 13.75 \\
20 & $4.70 \mathrm{a} \pm$ & 1.10 & 23.40 \\
50 & $4.06 \mathrm{a} \pm$ & 1.01 & 24.87 \\
100 & $8.25 \mathrm{~b} \pm$ & 0.52 & 6.30 \\
\hline
\end{tabular}

${ }^{*}$ means with the same letters are not significantly different at p > 0.05; RV - Relative Variance

Table 4. Estimation of O. florum adult density (number of flies/ $\mathrm{m}^{2}$ ) using the sweep-net method with samples of 10, 20, and 30 sweeps, Kostinbrod

\begin{tabular}{cccc}
\hline $\begin{array}{c}\text { Sampling } \\
\text { date }\end{array}$ & 10 sweeps & 20 sweeps & 30 sweeps \\
\hline 29.10 .2004 & $2.06 \mathrm{a}$ & $1.7 \mathrm{a}$ & $1.9 \mathrm{a}$ \\
02.11 .2004 & $1.7 \mathrm{a}$ & $4.3 \mathrm{~b}$ & $3.27 \mathrm{~b}$ \\
24.10 .2005 & $1.3 \mathrm{a}$ & $1.4 \mathrm{a}$ & $1.7 \mathrm{a}$ \\
26.10 .2005 & $2.8 \mathrm{a}$ & $2.7 \mathrm{a}$ & $2.5 \mathrm{a}$ \\
01.11 .2005 & $3.37 \mathrm{a}$ & $3.56 \mathrm{a}$ & $3.58 \mathrm{a}$ \\
07.11 .2005 & $7.5 \mathrm{a}$ & $6.45 \mathrm{a}$ & $6.37 \mathrm{a}$ \\
10.11 .2005 & $3.5 \mathrm{a}$ & $3.45 \mathrm{a}$ & $3.3 \mathrm{a}$ \\
\hline
\end{tabular}

*means with the same letters are not significantly different at $p>0.05$

However, the data on the relative error (RV\%) show particular differences between the variants. The value is highest in the variants with 10 sweeps, ranging from 9.65 to $35.38 \%$. In the variant with 20 sweeps, the relative error had the lowest values during the period of mass flight (5.8-6.61\%), while in the variant with 30 sweeps the error had the lowest values at the beginning of adult migration $(9.16-17.24 \%)$ (Fig. 9). Based on the results, the density of adults at the beginning of their migration should be calculated using 30 sweeps and during the period of mass flight - using 20 sweeps. Such an initial sample size with 5 repetitions, provides the accuracy required for mass observations (RV\% < 25\%).

\section{CONCLUSIONS}

1. O. florum is a pest on winter wheat, observed anually in Kostinbrod (Western Bulgaria). The population density of adults and damage rate of larvae are higher in wheat fields sown in the last decade of September and the first half of October. Fields sown during the first decade of November were not infested by the pest.

2. There are significant correlations between the mean temperature during the period of flight and the maximum density of $O$. florum flies within each sowing $(y=7.039+1.06 x, r=0.94, p=0.016)$ and between the percentage of damaged shoots and the maximum density of adults $(\mathrm{y}=4.13+6.85 \mathrm{x}, \mathrm{r}=0.96, \mathrm{p}=0.01)$ which can be used for prognostic purposes.

3. The higher amount of rainfall and lower mean temperatures in October and November resulted in a low population density, weak flight activity of adults during their migration to wheat fields, and a lower damage rate.

4. There were no significant differences in the mean densities of $O$. florum at different distances from the edge of wheat fields which have an even terrain. Therefore, sampling should be performed along the diagonal. On uneven terrain, the density of $O$. florum is significantly higher in furrows shielded from the wind. In such cases, a different sampling scheme should be used to take into account these patches and their total area.

5. An observation accuracy (RV\%) below $25 \%$ for O. florum adult density in the beginning of migration to wheat is obtained by using the sweep-net method with samples of 30 sweeps in 5 repetitions. During mass flight, adult density is most effectively registered with samples of 20 sweeps in 5 repetitions.

\section{REFERENCES}

Krusteva H. 2002. Studies on phenology, density dynamics and harmfulness of cereal and grass fly Opomyza florum F. (Diptera: Opomyzidae) on wheat in Southwestern Bulgaria. p. 131-134. In: Scientific Conference with International Participation "Stara Zagora 2002". Stara Zagora, 6-7 June, 2002, 360 pp.

Krusteva H. 2003. Density dynamics of Opomyza florum F. (Opomyzidae: Diptera) in winter wheat crops. Sampling methods. p. 108-112. In: Proc. International Scientific Conference "50 years university of forestry". Sofia, 1-2 April, 2003, 292 pp.

Krusteva H., Karadjova O., Beschovski V., Ventsislavov V. 2011. Studies on harmful dipterans on winter wheat in small grain regions of North Bulgaria. Plant Sci. 48 (3): 308-315.

Krusteva H., Ventsislavov V. 2004. Effect of winter wheat sowing date on degree of damages, caused by stem boring pests. p. 311-317. In: Scientific Conference with International Participation "Stara Zagora 2004". Stara Zagora, 3-4 June, 2004, 368 pp.

Krusteva H., Ventsislavov V., Nikolova G. 2006. Sowing date impacts the dipterous pests species composition and damage on wheat crop. Plant Sci. 5 (XLIII): 391-396. 
Ljubenov J. 1956. Opomyza - Opomyza florum F. as a pest on wheat. Bjul. po Rastitelna Zashtita 6-7: 87-88.

Mihailova P., Straka F., Apostolov A. 1982. Rastitelno-Zashtitna Prognoza i Signalizacia. Sofia, 342 pp.

Samfirov Z. 1961. Artenzussamensetzung und mauche biologishe Besourderheiten der Getzeidefligen im Bereich des Institute in Kneza. Mitteilungen des Allgemeinen Landwirtschaftlichen Forschungsinstitute. Kneza 1: 199-222.

Samfirov Z. 1966. Studies on the biology and control of yellow wheat fly. Rastitelna Zashtita 10-11: 22-26.

Short M. 1981. Damage assessment and chemical control of a grass and cereal fly (Opomyza florum). p. 431-440. In: Proc. British Crop Protection Conference - Pests and Diseases. Brighton, UK, 16-19 November, 1981, 930 pp.

Slope D. 1957. Opomyza florum on early sown winter wheat. Plant Pathol. 6, p. 110.

Southwood T., Henderson P. 2000. Ecological Methods. 3rd ed. Blackwell Science Ltd., 575 pp.
Stamenkovic S. 1980. Yellow wheat fly Opomyza florum Fabr. (Opomyzidae: Diptera) - a new wheat pest in Yugoslavia. p. 574-576. In: Proc. 3rd International Wheat Conference. Madrid, Spain, May 22 - June 3, 837 pp.

Thomas M. 1933. On the bionomics and structure of some dipterous larvae infesting cereals and grasses. Opomyza florum Fabr. Ann. Appl. Biol. 20 (4): 707-721.

Ventsislavov V., Krusteva H. 2006. Effect of planting date on density dynamics and damage rate of Opomyza florum Fabr. (Diptera: Opomyzidae) in winter wheat. Plant Prot. XVII: 54-62.

Vickerman G. 1982. Distribution and abundance of adult Opomyza florum (Diptera: Opomyzidae) in cereal crops and grassland. Ann. Appl. Biol. 101 (3): 441-447.

Zagovora A., Kravchenko A., Budennaja K. 1981. Opomyza on wheat. Zashtita Rastenii 10: 44-45. 